\title{
Milliliter per Deciliter
}

National Cancer Institute

\section{Source}

National Cancer Institute. Milliliter per Deciliter. NCI Thesaurus. Code C105504.

A measure of volume concentration expressed as the number of milliters of a dissolved substance per deciliter of solution. 